\title{
Marketing y publicidad cinematográfica El cartel de cine español
}

Marketing and Advertising Film The Spanish Movie Poster

\section{Rocío Collado Alonso}

Universidad Complutense de Madrid rcolladoalonso@gmail.com
Collado Alonso, R. (2015). Marketing y publicidad cinematográfica: el cartel de cine español.

Revista Internacional de Investigación en Comunicación aDResearch ESIC. No $11 \mathrm{Vol} 11$.

Primer semestre, enero-junio 2015. Págs. 58 a 77 DOI: 11.7263/ADRESIC.011.004 
El propósito de este texto es ofrecer una aproximación general a la Comunicación, Publicidad y Marketing cinematográficos, con el objetivo de revisar su evolución en las últimas décadas a consecuencia de la aparición de nuevos medios surgidos con la llegada de Internet y, sobre todo, con el concepto de web 2.0, y un acercamiento más detallado al cartel cinematográfico, tratando de establecer una aclaración teórica y conceptual del mismo, así como de sus características gráficas, formales y sus funciones, como unidades constituyentes de la identidad gráfica de cualquier filme, sobre la hipótesis de que sigue siendo una pieza clave y absolutamente vigente en el lanzamiento de un filme cinematográfico.

El auge de nuevos medios digitales ha favorecido el desarrollo de nuevas herramientas de marketing cinematográfico y ha conseguido que cada película exija nuevos retos de promoción para los distribuidores, quienes ahora consideran a Internet imprescindible para el lanzamiento de una película.

Ante esta situación, el cartel ha conseguido no sólo mantenerse como soporte esencial de promoción cinematográfica, sino que se va adaptando a estas nuevas tecnologías y medios digitales sin abandonar su puesto privilegiado a la entrada de la sala cinematográfica, dando a conocer la

JEL Classification:

M31, M37

Palabras clave:

communication,

marketing,

advertising,

poster,

cinema película y seduciendo al público, cumpliendo así sus funciones de rentabilidad y eficacia.

Desde un enfoque teórico, y desde un punto de vista comunicacional, se pretende ofrecer un texto que reflexione sobre los elementos constituyentes del cartel cinematográfico, estudiando sus dos lenguajes, el de los textos y el de las imágenes, tratando de descubrir las principales estrategias definidas en el plan de comunicación y que se resuelven en distintas destrezas compositivas repartidas por la superficie del cartel a criterio del diseñador, sin que sea necesario mantener un orden riguroso u ordenado, asociados de manera que formen una unidad, sencilla y unívoca en su lectura para que la decodificación del mensaje sea efectiva.
ABSTRACT

\section{Clasificación JEL: M31, M37 Key words:} Communication, Marketing, Advertising, Poster, Cinema
The purpose of this work is to provide a general approach to the Communication, Advertising and Marketing film, in order to check its progress in recent decades as a result of the emergence of new media emerged with the advent of the Internet and, above all, with the concept of web 2.0, and a more detailed approach to the movie poster, trying to establish a theoretical and conceptual clarification thereof and of its visual, formal and functions as constituent units of the graphic identity of any film on the hypothesis that remains an absolutely key and force in the launch of a movie film.

The rise of new media has encouraged the development of new film marketing tools and has managed each film promotion requires new challenges for distributors, who now consider the Internet essential to launch a movie.

In this situation, the poster has managed not only remain mainstay of film promotion, but adapts to these new technologies and digital media without abandoning its privileged position at the entrance to the cinema, advertising the film and seducing the public, fulfilling its functions of profitability and efficiency.

From a theoretical perspective, and from a communication point of view, is to provide a text that reflects on the constituent elements of the movie poster, studying their two languages, the texts and images, trying to discover the main strategies defined in the communication plan and working out in different compositional skills spread across the surface of the poster at the discretion of the designer, without having to maintain a strict order or direction, partners to form one unit, simple and unambiguous in its reading decoding the message to be effective. 


\section{Introducción}

El cine es un medio de entretenimiento y de ocio. Es técnica, es arte y es industria y, al igual que cualquier otro producto que se lanza a un mercado altamente competitivo, necesita utilizar distintas herramientas de comunicación, marketing y publicidad para darse a conocer y conseguir la mayor afluencia posible de público a las salas cinematográficas.

En los últimos cincuenta años, la oferta de actividades de ocio es cada vez más variada, y el consumo de este tipo de actividades también. Las nuevas formas de entretenimiento conviven con las más antiguas, coexistiendo todas juntas, por lo que la lucha entre ellas por conseguir al público es cada vez más dura. La industria cinematográfica no sólo se enfrenta a la propia competencia entre películas sino a todas aquellas otras fórmulas de ocio y entretenimiento que le roban protagonismo y mercado.

Por ello, el lanzamiento de una película requiere de fuertes inversiones en comunicación para darla a conocer en este mercado tan competitivo. Y el proceso de marketing comienza incluso antes de la propia creación del filme, pues cualquier productor debe plantearse cuestiones como el tipo de público al que quiere llegar, desde un punto de vista tanto cuantitativo como cualitativo, qué productos filmicos serán su competencia directa, cuáles serán los gastos de producción y los ingresos obtenidos con la película, cuándo se estrenará, etc. Así, antes de la comercialización de cualquier filme, es necesario saber posicionar adecuadamente la película. Para ello, se debe definir el género cinematográfico, qué concepto deberá conseguir el filme en la mente del público, qué estrellas serán las protagonistas y, como ya se ha comentado, el tipo de público que irá a verla.
Posteriormente, la campaña de comunicación y publicidad suele estructurarse en tres etapas secuenciales: prelanzamiento, lanzamiento y mantenimiento. Con la primera de ellas, se trata de generar expectativas en la audiencia. Así, antes incluso de empezar a rodar la película ya se han elaborado distintas fases de promoción que consisten en ir desvelando poco a poco pequeños detalles de la obra para suscitar el interés del público potencial y con el objetivo de estar siempre en el boca a boca de todos. Se enseñan fotos de producción, detalles del rodaje, posters promocionales, entrevistas en exclusiva en el plató de rodaje, etc. Incluso se lanzan todo tipo de campañas teaser con el objetivo de generar curiosidad y asegurarse cierta repercusión mediática. También la realización de press junkets (acciones promocionales especiales para captar la atención de los medios) y cuya finalidad es la construcción de publicity. Sirva de ejemplo la película «The Hobbit», de Meter Jackson, cuando un mes antes del estreno un Gollum gigante recibe a los pasajeros en el aeropuerto de Wellington, en Nueva Zelanda. Se trata de una estatua de unos 13 metros y casi una tonelada de peso, que intenta atrapar peces de 4 metros de largo y de su boca salen enormes burbujas de aire.

La fase de lanzamiento, con la película preparada para su visionado, está orientada en dos direcciones: bien hacia los canales de distribución cinematográfica, bien a la captación del público hacia la sala de cine para el propio consumo de la película. En el primer caso, se utilizan screenings (proyecciones especiales destinadas a profesionales), press-books, electronic press kit (especie de press-book electrónico), cartelería en varios formatos, etc. La seducción del público comienza con la información de la propia existencia de la película, de su estreno, incluso del 
pre-estreno, y su llegada a las salas cinematográficas. Hablamos del trailer cinematográfico, de spots de televisión, del making of, de cuñas en radio, cartelería, trade marketing (publicidad en la propia sala de exhibición con carteles, banderolas y troqueles de gran formato), comunicados en prensa y revistas especializadas, y todas las nuevas posibilidades de promoción y publicidad que ofrece Internet.

La última fase, el mantenimiento, se desarrolla en las fases posteriores al estreno de la película y va encaminada a mantener el interés por el visionado de la cinta y que la información boca-oreja siga circulando. Esta etapa puede prolongarse mucho más allá en el tiempo a la desaparición de la película de las salas de cine, manteniendo una lealtad hacia el filme y alargando su vida con productos como la edición de la banda sonora, libros, revistas, juguetes, ..., y todo tipo de merchandising.

Podemos decir que el cartel cinematográfico está presente en el lanzamiento de un producto fílmico desde el principio, desde que se empiezan a elaborar las primeras piezas de promoción para generar interés sobre una película. Cuando nace el cinematógrafo, el cartel comercial vive su etapa de mayor esplendor y es ya un medio consolidado para difundir los espectáculos, por lo que el cine va a recurrir a él desde el principio como herramienta de difusión y promoción ${ }^{1}$. Para Vernis (2003, p. 22) es: «...la pieza básica, más allá de romanticismos, ya que resulta el primer ejercicio de sintesis y concreción de todas las intenciones definidas para la comunicación. Su peso específico en el global de la campaña publicitaria ha ido

1 El origen del cartel de cine como medio publicitario se encuentra en el cartel de M. Auzolle para la película de los hermanos Lumière El regador Regado (L'Arrroseur Arrosé), de 1896, y ocupa el primer puesto en la historia porque parece ser que es el primero que elige para su composición un fotograma representativo de la película. descendiendo con el paso de los años a favor de otras piezas. Aunque nota un repunte de su relevancia debido a que, a raíz de la proliferación de las multisalas, la compra por impulso, y por tanto el traslado de la decisión y elección de la compra al último momento, está ganando protagonismo».

Es cierto que este soporte ha visto reducida su importancia en el lanzamiento de un filme con respecto a épocas pasadas. Se encuentra dentro de una campaña de comunicación global $y$, a su vez, dentro de un mercado fuertemente globalizado, por lo que las técnicas de promoción cinematográfica han ido evolucionando en los últimos años, al mismo tiempo que los nuevos medios y soportes de comunicación, adaptándose a los nuevos contextos y revoluciones sociales y tecnológicas. El público ahora demanda otro tipo de experiencias vinculadas a la propia película: contenidos exclusivos, mundos virtuales secretos para los fans, acciones de street marketing, aplicaciones especiales para tablets y teléfonos móviles, creación de avatares en las páginas oficiales, concursos, personajes en las redes sociales, promociones digitales, tráilers interactivos, vídeos exclusivos, chats sobre la película, etc.

Pero, sea como fuere el cartel de cine siempre ha sido la carta de presentación de las películas y una auténtica invitación para entrar a la sala cinematográfica.

\section{Planteamiento del estudio}

El propósito de este texto es ofrecer una aproximación conceptual y enunciativa del cartel cinematográfico como medio y soporte de promoción y publicidad de la industria cinematográfica así como un acercamiento a sus funciones y características, como unidades constituyentes de la identidad gráfica de cualquier filme, sobre la hipótesis de que sigue siendo una pieza clave y 
absolutamente vigente en el lanzamiento de un filme cinematográfico al margen de la aparición y desarrollo de formatos más novedosos llegados con la aparición de Internet y, sobre todo, con la interactividad que propicia el concepto de web 2.0.

De la gran diversidad de medios que puede utilizar una campaña cinematográfica, en este artículo se examina la forma y función del cartel de cine, sus elementos constituyentes y sus relaciones, así como sus funciones y sus características gráficas. Y todo ello con el objetivo prioritario de reivindicar su valor y alcance, su importancia como medio publicitario, dentro del total de la campaña.

\section{El cartel de cine}

\section{Definición}

Si partimos de la definición de cartel del profesor Eguizábal (2000, p. 89): «un anuncio de carácter oficial o privado, impreso sobre papel o tela que se fija o expone en un lugar público abierto o cerrado». Sin embargo, el cartel de cine tiene unas particularidades propias que le hacen distinto al cartel comercial. Por un lado, es un anuncio de un producto específico, la película cinematográfica, que según la Ley del Cine, cuyo texto es aprobado por el Congreso de los Diputados el 28 de Diciembre de 2007, se define como «toda obra audiovisual, fijada en cualquier medio o soporte, en cuya elaboración quede definida la labor de creación, producción, montaje y posproducción y que esté destinada, en primer término, a su explotación comercial en salas de cine. Quedan excluidas de esta definición las meras reproducciones de acontecimientos o representaciones de cualquier índole». Es por ello que, en un primer momento, el cartel cinematográfico informa del estreno o la proyección en los cines de la pelícu- la en cuestión. Pero, por otro lado, también puede informar de las características de ella: su personal creativo (actores y artistas que participen en la obra, director, guionista, director de fotografía, compositor de la música, etc.); técnico (director artístico, jefe de sonido, figurinistas, jefe de caracterización, montador, etc.); empresas de producción y distribución; así como también sobre el género o tema general de la película, mostrando relatos, personajes o decorados altamente codificados (es el caso por ejemplo del western, la comedia musical, películas históricas, de guerra, etc.) que aportan una referencia al público y cuya función es preparar al público para el posterior visionado del film así como servir de gancho publicitario para los espectadores afines a ese género.

Por otro lado, su ámbito de exhibición, tal y como afirma Pérez Perucha (1986, p. 12), es el otro aspecto que determina su materialidad sémica. Así, el cartel cinematográfico, además de verse sometido a la difusión estándar de cualquier cartel publicitario, se contempla más pausadamente en el propio lugar en el que se consumeel producto publicitado: la sala cinematográfica, «...favoreciéndose así no sólo la decisión de asistir al espectáculo, sino una mayor información sobre el mismo, ya que el hecho de consumir el cartel de forma más estática y tranquila que la que cabe esperar en el caso del 'affiche' comercial, (...) legitima un mayor grado de redundancia formal en su diseño, lo que se traduce en ese plus de información ya anotado».

También Pérez Perucha (Ibíd., p. 9-10) habla de otra diferencia que estriba en que el cartel de cine no necesita proclamar las cualidades del producto película, sino revelar sus características, teniendo en cuenta que los consumidores ya las conocen y valoran positivamente, es decir, no se trata tanto de listar las cualidades de uno u 
otro actor, sino de reflejar en el cartel su participación en la película anunciada.

No obstante, tal y como declaran Baldó y Vernís (2009, p. 60-61) «una película es un producto de consumo, clasificado como producto de compra esporádica, de ocio y sustituible por otra multitud de formas de ocio. Es una oferta que combina entretenimiento de una hora y media o dos horas, aproximadamente, con enriquecimiento personal, en muchas ocasiones», por lo que ellos establecen una relación de categorías a tener en cuenta como recursos más inmediatos para llamar la atención del público en la realización de una campaña de marketing de un lanzamiento cinematográfico y que obtienen de una encuesta de hábitos y prácticas culturales realizada en España en 2006-07. Según ellos, lo primero a tener en cuenta es lo que denominan «talentos», que engloba a todo el elenco creativo que participa en el filme, desde actores hasta directores y productores, seguido del argumento, los géneros cinematográficos, o lo que llaman legitimadores que son elementos tales como la crítica o los premios recibidos en determinados festivales.

La importancia del cartel cinematográfico radica entonces en conseguir una auténtica labor de síntesis, es decir, una combinación nueva, ingeniosa y coherente de los distintos elementos que conforman cada película. Es un medio de comunicación y un instrumento de persuasión, por lo que cumple dos objetivos: por un lado, informa, de ahí que utilice el código textual para título, actores, director, etc., y por otro lado usa la imagen para persuadir e inducir al consumo de este producto. Se compone, por tanto, de elementos textuales y visuales que conforman el mensaje final: anunciar la película en cartel.

\section{Funciones y características}

En 1973 Abraham Moles con su libro L'Affiche dans la Societé Urbaine, nos deja claro cuáles son las funciones del cartel publicitario: la función de información, pues lo considera un canal que conecta a emisor y receptor dando a conocer artículos de consumo; la función de convicción, en tanto que trata de cambiar el comportamiento del consumidor; la función económica, pues genera motivaciones que impulsan la compra; la función estética, a través del lenguaje y la retórica visual; la función creadora, ya que crea en el receptor nuevos rutinas perceptivas; y la función ambiental, en tanto en cuanto se convierte en un elemento más del paisaje urbano.

Sin embargo, si analizamos el cartel cinematográfico podemos establecer una serie de funciones que lo delimitan y le otorgan su especificidad. Así, en primer lugar, es evidente que debe aportar una información al espectador en cuanto al producto anunciado, pero también tiene que conseguir seducirle y convencerle para entrar en la sala, por lo que debe ser honesto en relación a la información proyectada en la superficie compositiva a fín de que el público no se sienta traicionado, pues una vez vista la película el cartel se conceptúa en relación a ella y debe ser capaz de reafirmarla. Como bien dice García García (2007, p. 167): «La publicidad hace más inteligible el producto y más deseable. Crea las condiciones de verosimilitud y credibilidad concediendo una identidad original al producto, ofrece una perspectiva nueva y atractiva. La publicidad es el arte de vender persuadiendo».

Por otro lado, el cartelista cinematográfico debe ser capaz de crear, dentro de cada estilo personal y particular, narrativo y estilístico, una composición gráfica llamativa e impactante que genere deseos y necesidades en el espectador. El cartel 
expone la película, pero también induce a su visionado, por lo que el artista debe utilizar todos aquellos recursos más demandados por el público (acción, violencia, sexo, humor,...), pero también atender los requerimientos de productores, distribuidores, actores, etc. Y todo ello con una labor de síntesis e inteligencia que convierta al cartel en único y excepcional.

Se trata de un cartel cinematográfico, que continuamente remite al espectador al mundo del cine con sus encuadres, ambientes o escenarios, pero no hay que olvidar que también es publicitario, por lo que tiene que cautivar y seducir rápidamente con una imagen fija.

Un cartel de cine depende de muchos factores, algunos más técnicos, como el estilo del propio cartelista o el medio utilizado para su reproducción, y otros más subordinados al producto que publicita, como el género de la película, su argumento, las imposiciones estilísticas de las productoras, los actores principales, etc., pero tiene que conseguir ser él mismo un espectáculo capaz de crear una unidad de estilo entre la película y el público.

Además, debe vender bien su producto. Debe de ser bello, pero también adecuado para lo que fue creado. Debe recoger toda la información necesaria para la «venta» del filme, pero ha de hacerlo sin atender a esquemas, estereotipos o ideas temáticas preconcebidas, sin mediocridad en su diseño, en su código cromático o tipográfico.

\section{Lenguaje}

\subsection{Código textual}

Aunque en el cartel se suman dos lenguajes, el de las imágenes y el de los textos, es sabido que el cartel es, sobretodo, imagen, y ésta se constituye, como ya afirmaron Enel (1974, p. 22) y Moles (1976, p. 19), en un «estímulo fuerte» que atrae poderosamente al ojo humano. Tiene mayor poder de atracción y seducción que el texto pero, sin embargo, puede alcanzar altos valores de polisemia que hay que clarificar y va a ser, precisamente, este texto, un estímulo visual mucho más débil, el responsable de corregir las confusiones generadas por la imagen, amplificando y/o puntualizando el mensaje para que éste se transmita de manera idónea.

Como ya dijimos anteriormente, Enel (1974, p. 27-48) compendia las teorías marcadas por Abraham Moles en cuanto a las funciones principales que tiene todo cartel: informativa, de persuasión, económica, ambiental, creadora y estética, y nos vamos a detener en este punto tan sólo en las dos primeras. Inicialmente en la informativa, ya que es el texto, pese a ser un estímulo visual mucho más débil que la imagen, el principal elemento responsable de llevar a cabo esta función, completando y matizando el mensaje lanzado a través del código visual, concretando en lo posible la polisemia de las imágenes. Según Alcocer Garmendia (1991, p. 12) «en el sistema icónico-literario del cartel, el texto, en relación a la posible ambigüedad de las imágenes, aclara y fija el sentido, o lo refuerza dándole mayor alcance, o lo matiza ampliamente». Y también Enel (1974, p. 73) insiste en esta idea: «el texto utilizado por el publicista está enfocado por completo hacia un único fin: cristalizar una significación entre todas las significaciones posibles de la imagen».

Asimismo, el texto se ocupa de añadir otras informaciones (productora, distribuidora, equipo técnico, etc.) que rematan el anuncio y, a su vez, contribuyen a reforzar la siguiente función: la persuasiva. A nivel ligüístico, según Enel (Ibíd., p. 34), el cartelista dispone de una serie de técnicas (amenaza, sugestión, orden, asociación, argumentación, etc.) que puede aplicar en el eslo- 
gan o la frase publicitaria, por ejemplo, y que ayudan a elaborar un cartel convincente.

Como ya se ha comentado, el cartel cinematográfico anuncia una película, por lo cual el texto deberá mostrar aquella información y/o argumentos que mejor definan este producto a vender. Por eso, los elementos textuales que suelen mostrarse en un cartel de cine son: el título, el director, la productora, la distribuidora, (estas dos últimas con o sin identidad visual corporativa), los distintos protagonistas, principales y secundarios, el eslogan o frase promocional, las novedades técnicas, el equipo técnico, el público al que va dirigida la obra, los premios recibidos en distintos festivales, la página web en los últimos años, etc. Pese a que son textos meramente informativos, en determinadas ocasiones, algunos de ellos, como es el caso de los protagonistas, el director o productor, son un reclamo mucho mayor que la propia imagen, por lo que se les da mayor peso en el diseño gráfico.

Sin embargo, no es necesario ni obligatorio que aparezcan todos ellos, sino que cada época, cada cultura o cada película concreta, entre otras razones, van a ir marcando unas pautas.

En cuanto a sus características formales y de composición, cabe decir que, la propia naturaleza del cartel hace que la comprensión de su mensaje sea prácticamente inmediata, por lo que los textos deben ser considerablemente cortos para que su lecturabilidad no se vea perjudicada en función del tiempo que el posible espectador le dedica. Pueden disponerse por toda la superficie del cartel pero, sin embargo, hay que señalar que la posición de los textos dentro del cartel también adquiere un valor importante. Su colocación en la parte superior de la superficie a diseñar les otorga una importancia mucho mayor que si, por el contrario, son situados en la mitad inferior. No obstante, muchas veces esa importancia dependerá de su lectura en relación a la colocación del resto de elementos textuales y visuales que conforman el diseño.

También el tamaño juega un papel significativo. Los textos aparecidos deben tener unas proporciones adecuadas para que puedan leerse a cierta distancia pero, de todas formas, viene determinado por la trascendencia de los componentes que representa y quedará determinado por la importancia de éstos en la información a transmitir.

Del mismo modo, es importante la elección de una buena tipografía que despierte el deseo de leer y reduzca el esfuerzo requerido de comprensión. Observamos tipos de lo más variados, desde versiones más humanistas, con formas matizadas o más caligráficas, hasta modelos más conceptuales, sintéticos o gráficos, pero siempre letras visibles, con formas bien definidas, y con colores y contraste adecuados.

\section{Elementos textuales en el cartel cinematográfico}

Los elementos textuales que conforman el cartel cinematográfico han variado mucho a lo largo de su historia: denominación de la película, del director, actores y actrices principales y secundarios en algunos casos, empresa productora (a veces con su identidad gráfica visual), miembros del equipo técnico destacados (especialmente en fotografía), novedades técnicas, premios recibidos, eslóganes o frases publicitarias, y datos relativos al propio cartel (depósito legal, autoría, lugar de impresión, etc.). Y todo ello haciendo un verdadero uso efectivo de la tipografía, dándole forma visual y buscando el equilibrio entre el dibujo y el propio texto. 
Los elementos que mayor importancia tienen para la promoción de la película son el título y los nombres de los protagonistas principales. Es por eso que pasamos a detallarlos a continuación.

\section{Título}

Es aquella palabra o frase que da a conocer el nombre de la película. Debe definir y precisar la obra que anuncia dando así sentido al cartel anunciador al completar la lectura del mensaje. Es el elemento tipográfico más importante, por lo que recibe un tratamiento gráfico especial, de mayor tamaño y peso específico, distinto al resto de elementos textuales que aparecen en el cartel cinematográfico. Según Perales Bazo (1999, p. 96) el título busca principalmente dos fines: denominar e identificar la película y además, su mayor difusión posible.

Mientras que en los primeros años de uso del cartel cinematográfico, únicamente se buscaba la identificación del producto (película), es a partir de los años 30 cuando se empieza a dar un aspecto más visual al texto correspondiente al título, de tal manera que se convierte en un nuevo signo gráfico.

También Perales Bazo (1995, p. 92) afirma que «La forma, el tamaño, el color y la disposición del material tipográfico tienen que poseer una imagen poderosa y atractiva. La organización de estos efectos deben convertir el mensaje en su reflejo visual». El título se transforma en un sugerente y descriptivo elemento visual, que queda influenciado por la trama argumental, el propio significado de las palabras que lo conforman, la estética del filme y las imágenes que lo acompañan. Así, este texto aúna dos aspectos: transmitir el significado propio de las palabras y simbolizar con su visualidad aquellos otros contenidos relativos al género cinematográfico o al propio argumento del filme, por ejemplo.

Los aspectos trabajados por los distintos diseñadores de carteles para otorgar al título esa capacidad visual son los referidos a la elección adecuada de la propia tipografía, su tamaño, su color y su disposición dentro de la superficie del cartel. No hay normas, más que las marcadas por el éxito del modo de hacer norteamericano y que van a influir en los gustos de las distribuidoras nacionales y, por supuesto, aquéllas que se impone el propio cartelista.

Así, dependiendo de cada película, de su director, de la distribuidora o productora, pero también en función de cada época o género concreto y, por supuesto, del estilo gráfico de cada cartelista, la trascendencia de la elección tipográfica y sus valores estéticos nos ha dejado ejemplos muy variopintos: desde trazos gruesos, sólidos y pesados hasta versiones mucho más estilizadas, condensadas y alargadas; mayúsculas y minúsculas, cursivas y romanas, conviviendo y aportando variedad; opciones bidimensionales o tridimensionales, ofreciendo versiones planas o resaltadas, sombreadas o contorneadas; tipos simplones y aburridos frente a otras letras sorprendentes, llamativas, sugerentes, atractivas y variadas.

Puede ocupar más o menos espacio en la superficie del diseño. Unas veces se busca el impacto visual dándole al título un tamaño formidable mientras que otras se pone todo el esfuerzo en la elección adecuada de las letras, en cuanto a rasgos $\mathrm{y}$ aspecto, y no tanto en su formato.

Por supuesto que tampoco hay normas para el componente cromático, salvo la exigencia, casi siempre buscada por los dibujantes, de otorgar un tratamiento de color específico a estos textos sin perder el equilibrio necesario con el resto de los elementos de la composición: colores lisos o degradados, apagados o brillantes, armó- 
nicos o estridentes, buscando continuamente la combinación perfecta.

Su disposición en el cartel ha estado habitualmente marcada por una notable horizontalidad, tolerando en ocasiones ligeras inclinaciones que no perjudicaran su estabilidad y lectura. Se puede colocar en la parte superior del cartel, en su base o en el centro, siempre lugares estratégicos que buscan un mayor poder de captación visual y, sobre todo, que este texto resulte integrado en el contexto de la composición. No obstante, de la misma manera puede funcionar de manera autónoma. No se persigue ese vínculo entre todos los elementos, sino que se dota al título (denominación del filme) de la suficiente fuerza expresiva para que actúe por sí mismo.

Precisamente, y como ya manifestara Rey (1997, p. 13) «...en el sistema publicitario, el signo gráfico se convierte en escritura y simultáneamente en pintura. La publicidad pretende que el trazo gráfico no sólo sea leído sino también visto». Por lo tanto, lo más habitual es que el título se transforme en una pieza visual que completa y remata la totalidad del mensaje, no sólo porque acompaña a la imagen sino también porque aporta significados. Así, según Rey (Ibíd., p. 10) el «código escrito se materializa en unos trazos - las letras - cuyo aspecto visible, además del significado convencional, puede aportar un significado extralingüístico gracias a su capacidad figurativa». Vemos entonces cómo el título, haciendo uso de ese potencial simbólico que tiene el texto, se convierte en un elemento gráfico con mayor expresividad conceptual, aportando valores como romanticismo, religiosidad, alegría, terror, etc. El cartelista juega con la forma de las letras, con su tamaño, color y disposición espacial para simbolizar figuras u objetos que hagan referencia al género o argumento del filme; añade ornamentos y decora las letras, incorpora elementos gráficos, sustituye letras por signos y todo para aumentar el grado de significación del texto.

Asimismo podemos anotar la notable codificación visual establecida para ciertos géneros cinematográficos. A lo largo de la historia del cartel cinematográfico, se han establecido y generalizado algunas «normas» o pautas tipográficas a seguir, que se han convertido en tópicos, en un estilo especial para géneros concretos, es decir letras rojas y ensangrentadas para el género de terror, metálicas y futuristas para ciencia-ficción, gruesas y tridimensionales para el bíblico, góticas para el género histórico, etc.

No obstante en los últimos años, seguramente por el uso abusivo e indiscriminado de determinado software, se ha viciado en gran medida el estilo tipográfico del título, buscando únicamente soluciones funcionales, prácticas y facilonas que quedan muy lejos de los atractivos y sugerentes planteamientos anteriores.

\section{Protagonistas}

Nos referimos a las personas que interpretan a un personaje en una película cinematográfica. El nombre de estos actores es, junto con el título, uno de los elementos tipográficos más importantes en el diseño del cartel y, como comentábamos anteriormente para el título, la historia del diseño cinematográfico ha dejado cuantiosas muestras relativas al tratamiento tipográfico recibido por estos textos. También la elección de las letras, su forma, color y disposición en la composición va a estar trabajada de manera que quede integrada en el conjunto del diseño.

Aunque es un texto meramente informativo, en algunas ocasiones el nombre de estos protagonistas, incluso del director o el productor, son un reclamo en el conjunto del cartel mucho mayor que la propia imagen o el título, por lo que 
se les da mayor peso y visibilidad en el diseño gráfico.

Interviene aquí el conocido fenómeno del Star System, que ha condicionado tremendamente el tratamiento textual que se ha dado al nombre de los protagonistas del filme. Star System es una expresión inglesa que hace referencia al sistema de contratación de actores en exclusividad y a largo plazo que realizaban los estudios cinematográficos americanos para asegurarse el éxito de sus películas y que empieza a funcionar hacia los años treinta. Estos estudios crearon a la estrella del cine, una mezcla de personaje y actor, que han sido mitificados extraordinariamente por parte del público.

Parece ser que fue el director de cine norteamericano David Wark Griffith quien empezó a firmar sus películas y a colocar a los actores en los títulos de crédito. Por ello, los actores empezaron a ser conocidos y demandados por parte del público. Y este fenómeno ha llegado hasta nuestros días, de tal forma que muchas películas ganan o pierden relevancia inicial en función de sus protagonistas.

Según Perales Bazo (1999, p. 112) «...las estrellas y sus representantes defienden y clasifican, incluso antes de firmar los contratos, el modo y el orden en que aparecerán sus nombres, no solo en el film, sino también, y esto es muy importante para ellos, en todos los tipos y medios publicitarios utilizados para el lanzamiento del film». Esto ha sido motivo de no pocos conflictos pues las estrellas no aceptan un tratamiento gráfico desigual — justificado por razones como la importancia del personaje representado o el tiempo de actuación de uno u otro actor- que puede perjudicar a su estatus profesional.

Es por ello que se han establecido acuerdos que tratan de regularizar de manera equilibrada el tratamiento gráfico a recibir por parte de los actores y que Perales Bazo (Ibíd., p. 116-120) resume de la siguiente manera:

- Cuando el reparto está formado por dos o más estrellas de categoría equivalente. En este caso se procura que sus nombres reciban un tratamiento gráfico idéntico, tanto por la tipografía utilizada, como por tamaño, color y ubicación.

- Cuando el reparto está integrado por protagonistas de similar estatus profesional, pero se les da una solución gráfica desigual, es decir, reciben la misma tipografía, tamaño y color, pero la estrella principal queda aislada, se le da una ubicación preferente y con ello, mayor notoriedad.

- Cuando el reparto está constituido por una única estrella y es entonces cuando ésta recibe un trato muy especial: tipografía de enormes proporciones y recursos gráficos concretos que le otorguen mayor visibilidad.

- Cuando el reparto cuenta con la colaboración excepcional de un actor o actriz de renombre que se contrata para un pequeño papel pero que le da a la película mayor prestigio comercial. En este caso es necesario remarcar gráficamente su intervención pero dejando ver que es una contribución puntual para que el posible espectador no se sienta engañado.

\subsection{Código visual}

Moles (1976, p. 141) define el cartel como «...una imagen capaz de crear numerosas connotaciones o evocaciones, inciertas pero atractivas, cristalizadas por un texto breve de palabras muy legibles». Pero también (citado en Garófano, 1989, p. 45): 
«imagen coloreada portadora generalmente de un único tema y acompañada de un texto líder que rara vez excede de veinte palabras y expone un único argumento. Normalmente está hecho para ser pegado y expuesto a la vista del público».

Del mismo modo, para Alcocer Garmendia (1991, p. 11): «en el cartel, se aúnan dos lenguajes: el icónico y el literario». Por lo tanto, los elementos principales de un cartel: la imagen y el texto y su esencial conjunción, relacionándose de tal forma que crean un nuevo y único lenguaje.

Es sabido que la imagen posee un mayor poder de atracción y seducción, por su colorido, su composición, su encuadre, su dinamismo, etc., y capaz de cautivar más rápidamente al público que debe leer el cartel. Pero, si se comunica sólo con imágenes, el volumen de significados puede verse muy aumentado, y esta polisemia puede hacer que se pierda el auténtico sentido del mensaje, ya que la eficacia del cartel cinematográfico reside en el reconocimiento por parte del público de la película anunciada.

Según Vidal Silva (2006, p. 97) la publicidad moderna se define cuando «se dota de imágenes que hacen posible la expresión visual y simplificada de ideas conceptuales y abstractas para promoción de los productos». Por lo que es en este momento cuando la imagen pasa a ser el elemento más importante de la publicidad y, por ende, del cartel.

No obstante, el cartel cinematográfico tiene unas particularidades que le hacen distinto. Según Tranche (1994, p. 138): «... las peculiaridades de la industria cinematográfica convertirán al cartel de cine en un género específico. En él, el referente ya no es un objeto o una idea sino otra imagen. El diseño del cartel de cine debe evocar, sugerir las imágenes del universo cinematográfico (por tanto, actúa como principio de condensación, en clave metonímica)».
La imagen del cartel de cine, por tanto, está representada por unos iconos que se establecen mediante la adecuada combinación de símbolos, figuras, su gestualidad ${ }^{2}$, colores, etc. Efectivamente, este cartel es un mensaje, principalmente construido con elementos icónicos, pero esta iconicidad puede tener distintos niveles de representación, desde lo más concreto hasta lo más abstracto, aunque esta última opción no es habitual por correr el riesgo de ser ininteligible para el espectador.

Algunos autores ya han apuntado esta idea, de tal forma que Vidal Silva (2004, p. 47) afirma que existen dos maneras de comunicar el tema de una película que determinan las dos tendencias de contenido: la norteamericana y la europea: "El cartel norteamericano tipo Hollywood, que representa a los actores y tal vez ilustra una escena característica de la película. Basado en el "star-system» y en la foto "glamour», se ha convertido en un tipo de cartel estándar, donde se diluye la noción de autor al recurrir a una fórmula representacional, con recursos fáciles y previsibles, sacrificando incluso los iconos típicos de cada género, en beneficio de una mayor «sapiencia» de los protagonistas. (...) El cartel conceptual europeo, más centrado en el significado global de la película, en su contenido, en el concepto o idea principal que trata de simbolizar, recurriendo a la alegoría, la metáfora y otros recursos representaciones reales más imaginativos que en el primer caso. Es así una interpretación del artista, a quién no le basta con un simple fotograma del film para realizar el cartel, sino que precisa haber visto la película para construir la imagen simbólica que, de manera sintética, la represente".

2 El profesor Pedro Vidal (2007, p. 112) habla incluso de la alta significación que puede adquirir la gestualidad de los actores: «...manos expresivas y enfáticas, y caras mayoritariamente sonrientes, o gesto serio pero sin gravedad (...) Ojos, boca, postura facial y peinados se convierten en elementos significantes». 
También Tranche (1994, p. 138-139) manifiesta que las técnicas y estilos empleados por los distintos cartelistas han pasado de un tratamiento eminentemente pictoricista y conservador en los primeros años a una rápida incorporación, a partir de los años veinte, de los estilos de las distintas vanguardias artísticas, como el fotomontaje, el cubismo, el Art Decó, el Pop Art, etc., y también de la propia técnica cinematográfica, en cuanto a la aplicación de planos, escala y angulación, iluminación, etc. Seguidamente, señala lo que para él han sido las dos líneas claras de composición del cartel cinematográfico, opciones que se han mantenido hasta la actualidad:

- La primera, aquélla que expresa la temática de la película mediante representaciones alegóricas, rechazando la imitación de la iconografía del propio filme. Por supuesto que los ejemplos que aquí señala no podrían ser otros que los carteles del cine alemán de los años 20 y 30, los del cine soviético, el cartel polaco y el cubano.

- La segunda, más frecuente sobre todo en el caso español, es aquélla más realista, más centrada en representar de manera constante escenas concretas de la película, y sobre todo tremendamente influida por el fenómeno del star-system, apareciendo la o las estrellas siempre en primerísimo primer plano. Se vuelve, entonces, al retrato, pero acompañándole de escenas de acción en distintos planos que recuerdan la técnica cinematográfica del montaje. Es una composición de fácil lectura por la adecuación ordenada de todos los elementos dentro del cartel (imagen y texto).

Sin embargo, aunque el cartel de cine ha sufrido muchas transformaciones, estamos de acuerdo con Pérez Perucha (1986, p. 11-12) cuando habla de unas características que le identifican y van a permanecer siempre, que son la estructura narrativa, el star-system y la visualidad de la película.

Lo que nos atrae del cine es el relato, la organización y relación de los distintos elementos que conforman la trama argumental, por eso podemos decir que, en cuanto a la estructura narrativa, los carteles cinematográficos tienen que comunicar a los posibles espectadores las claves que delimitan la película anunciada. El público necesita ver determinados indicios que le permitan discernir mínimamente el contenido argumental o el género cinematográfico, por ejemplo. Es indudable que algunos de estos géneros, como el western o el thriller, han conseguido atesorar una serie de iconos, rasgos y estilos que el público va a diferenciar claramente.

No obstante, Perales Bazo (1999) sostiene que la publicidad cinematográfica siempre ha estado dirigida al público femenino ${ }^{3}$, pues parece ser que siempre es la mujer quien tiene la última palabra a la hora de decidirse por una película u otra. Es por ello que, prácticamente desde la década de los años 30, los grandes estudios americanos - y por ende, la industria española—, teniendo en cuenta los gustos y preferencias del público femenino y masculino, llegan a ofertar dos carteles diferentes para una misma cinta: en uno de ellos, la versión masculina, se elige una iconografía que represente aventura, espectáculo y acción, mientras que en el otro se trata siempre de resaltar el asunto amoroso y romántico ${ }^{4}$. Lógicamente esta solución, conveniente efectiva por

3 Basa su afirmación en las declaraciones efectuadas por Alfred Hitchcock en una entrevista que le realiza François Truffaut y que fue publicada en 1967 con el título «El cine según Hitchcock».

4 Perales Bazo (1999, p. 132-134): Este autor establece incluso una categoría de iconos que aparecen en el cartel cinematográfico para representar la idea de romanticismo: corazones que se integran en el 
abarcar los gustos de un mayor porcentaje de público, supone un coste de promoción muy elevado por lo que pasa a usarse en contadas ocasiones, pero se toma entonces una medida intermedia: difundir el doble mensaje en el cartel, utilizando la parte superior para los aspectos más románticos y la inferior para las escenas de aventura y acción.

Desde entonces, esta manera de componer el cartel cinematográfico se convierte en una especie de norma a seguir, extendiéndose a todo tipo de películas, independientemente del género y argumento.

De igual manera, Perales Bazo (Ibíd., p. 136140) habla también de la exigencia de representar, más o menos implícitamente, determinados indicios relativos a la pasión y el deseo sexual. Enumera una serie de aspectos que se atribuyen a los protagonistas, especialmente los femeninos, como: la mirada soñadora y perdida en el horizonte, labios entreabiertos que otorgan a los personajes un importante poder de seducción, o vestirles con una indumentaria tremendamente ajustada que aporta un matiz más erótico. Según el autor, es fundamental también para transmitir esa apariencia sensual, una buena elección de los actores, para que los cartelistas utilicen la propia sensualidad de cada persona.

Respecto a la visualidad del film, afirma Hueso Montón (2011, p. s/n) que en el cartel cinematográfico confluyen dos cuestiones: los factores publicitarios y de reclamo y aquéllos que hacen referencia a la fuerza de la imagen y la búsqueda de la belleza estética. Es necesario que el cartelista encuentre un buen equilibrio entre la información textual y la imagen que se utiliza para la promoción de la película para conseguir el fin

contexto visual, lunas sonrientes, un teléfono (icono que representa a la comedia rosa americana) y flores. último del cartel: "porque el dinamismo del dibujo, la riqueza de matices con que se presentan las acciones y los personajes, la búsqueda de unas imágenes que puedan impactar y seducir al espectador, el uso del grafismo y del color de acuerdo con criterios estéticos precisos, la adecuación a las premisas concretas de la sociedad a la que va dirigido el cartel (...), son elementos que deben integrarse dentro de una totalidad unitaria a fin de alcanzar la finalidad que preside su construcción».

Por último y como hemos comentado anteriormente con el código textual, el acontecimiento conocido como star-system condiciona enormemente la composición del cartel de cine desde el momento mismo de su aparición, de tal manera que el elemento principal del diseño va a ser casi siempre la o las estrellas protagonistas del filme, representadas en distintas fracciones y escalas, afectando sobremanera al modo de hacer de los cartelistas, que perderán su libertad creativa. Este fenómeno aparece y se establece firmemente en Hollywood pero rápidamente se extiende por el resto del mundo, incluida España, por supuesto.

La estrella se convierte en el signo icónico de mayor reclamo. Sánchez López (1997, p. 64) afirma que lo importante en los carteles que contienen estrellas es que: «Pueda reconocerse rápidamente a las stars, que son los mejores y los más seguros reclamos del film. El estilo es realista, sin demasiadas preocupaciones estéticas».

A partir de este momento, el procedimiento repetido por la mayoría de cartelistas consiste en recortar, estilizar y engrandecer la figura principal, colocándola en un lugar destacado, para darle mayor importancia y atractivo que al resto de los elementos compositivos, que quedan manifiestamente olvidados. 
Este fenómeno afecta tanto al diseño y creatividad de los carteles de cine que incluso, como anteriormente comentábamos en el caso de los elementos textuales, los propios actores van a imponer sus reglas. Perales Bazo (1999, p. 142) lo resume de la siguiente manera: «Las grandes estrellas de Hollywood, conscientes de la enorme importancia de su presencia en el diseño publicitario, comenzaron a opinar y exigir una serie de condiciones que les fueran beneficiosas. Por tal motivo incluyeron cláusulas en sus contratos para poder revisar, exigir y dar el visto bueno en cuanto a la representación de su propia imagen. El actor de mayor popularidad y prestigio imponía que su figura estuviera situada en un plano privilegiado con respecto a los demás actores y exigía que el tamaño de los rostros mantuvieran relación con la categoría que tenían».

Casi siempre, la principal tarea del cartelista consiste entonces en integrar personaje y actor en una misma imagen y tratar de salvaguardar las cualidades personales que a estos personajes les han convertido en estrellas. Perales Bazo (Ibíd., p. 170): «En todo afiche aunque su diseño ineludiblemente remita a los valores intrínsecos del producto, existe una intención de interpelación con otros que le son afines. Al ser responsable, al menos en parte, de la respuesta comercial también lo es del glamour de sus estrellas. El cartel no permanece estático en sus interpretaciones $y$, por consiguiente, no se somete estrictamente a su producto; el dibujante no se limita a representar los rasgos del protagonista y los elementos más sobresalientes de su caracterización, sino que hace una sintesis de ellos, acentúa las cualidades y atributos que lo hicieron popular».

Del mismo modo Tranche (1994, p. 141) hace especial referencia al tratamiento del rostro en los carteles de cine, que se guiará por la técnica del flou fotográfico, para endulzar rasgos y contornos y así no se advierta el paso del tiempo en los protagonistas. También la mirada, perdida, extraída de la composición, como si los personajes estuviesen distraídos, ajenos al resto de los elementos que aparecen en el diseño.

La representación en el cartel cinematográfico de estas estrellas se generaliza de tal forma que podemos hablar de soluciones habituales, independientemente de la película anunciada, su temática, género e, incluso, del cartelista. Perales Bazo (1999, p. 161-162) recopila las más comunes:

El uso del personaje protagonista como tema principal del diseño y su relación con los actores, de tal forma que se fusionan en una única imagen.

- El uso del rostro de la estrella como el elemento icónico de mayor reclamo, con la única finalidad de favorecer aún más su reconocimiento.

- El uso de un tratamiento cromático específico, tanto en el fondo de los carteles (ya sea de color liso o neutro), como en la propia imagen del protagonista, cuyo resultado es un significativo aumento de la fuerza expresiva del dibujo.

- El uso del cuerpo entero de la figura protagonista, sólo en aquellas ocasiones en las que el rostro de la estrella no es suficiente reclamo o bien porque el efecto buscado es resaltar la sensualidad y atributos eróticos del protagonista, casi siempre una figura femenina.

En cuanto a los recursos compositivos de los carteles, Perales Bazo (Ibíd., p. 162-198) establece la siguiente clasificación:

- Cuando la composición está dominada por escenas representativas del argumento de la película pero, además, se reconoce convenientemente a los protagonistas. 
- Cuando la composición se basa estrictamente en la presencia de los actores, pero éstos no aluden, o lo hacen de un modo muy liviano, al contenido argumental.

- Cuando la composición mezcla los dos recursos anteriores: figuras o rostros de los protagonistas y sus conexiones, además de la presencia de una o más imágenes que enlacen a los anteriores con el contenido argumental.

Pero posiblemente sea Serrano Mora (2009) quien más puntualiza a la hora de establecer una clasificación en cuanto a las iconografías utilizadas en el cartel de cine, por lo que nos atenderemos a ella:

- Una escena o fotograma de la película.

- Varias escenas de la película.

- Un solo protagonista sobre fondo neutro.

- Un solo protagonista con fondo concreto o escena/s de la película.

- Pareja de protagonistas sobre fondo neutro.

- Pareja de protagonistas con fondo concreto o escena/s de la película.

- Grupo de personajes sobre fondo neutro.

- Grupo de personajes con fondo concreto o escena/s de la película.

- Composición con grupo de objetos o importancia de la tipografía.

\subsection{Interrelaciones entre ambos códigos}

El cartel cinematográfico es un medio de comunicación y un instrumento de persuasión, por lo que cumple dos objetivos: por un lado, informa, de ahí que utilice el código textual para título, actores, director, etc., y por otro lado usa la imagen para persuadir e inducir al consumo de este producto, la película. Se compone, por tanto, de elementos textuales y visuales que conforman el mensaje final: anunciar la película en cartel.

Según Gómez Pérez (2002, p. 204) el cartel de cine propone dos lecturas: una denotativa, constituida por la información aportada y otra connotativa, por su capacidad persuasiva. Y cita seguidamente a Enel (1977, p. 16): «El cartel no debe ser solamente argumental, sino sobre todo sugestivo, insinuante. Combina en el seno de una misma configuración símbolos intencionales que constituyen el enunciado de la denotación: representación del producto, sus funciones, sus cualidades... y símbolos interpretativos que constituyen el enunciado de la connotación: un dato cultural o estético que va a provocar en el receptor reacciones afectivas y elaborar un mundo suprasensorial, desbordando el ámbito de los signos». De esta manera, arte, comunicación y publicidad se complementan para formar el mensaje del cartel cinematográfico.

La imagen, más sugerente y atractiva, tiene mayor poder de atracción y, sobre todo, de connotación, por lo que necesita del texto para fijar correctamente el mensaje. Pero hay que decir que ambos códigos informan y persuaden. Según Perales Bazo (1995, p. 92): «En todo afiche están contemplados los valores temáticos del filme, ya sea mediante las imágenes que configuren el cartel o a través de los rótulos y las frases publicitarias que se contengan en él o ambas cosas a la vez». Es decir, la información sobre los protagonistas de la película puede venir dada tanto por la aparición de su nombre en el cartel, como por la representación de su rostro. Y lo mismo ocurre con la información textual: una frase publicitaria en el cartel puede tener el mismo valor connotativo que la propia imagen.

El fin último del cartel es comunicar y por ello, todos los elementos que lo componen, visuales y textuales, se reparten por la superficie del cartel 
a criterio del diseñador, sin que sea necesario mantener un orden riguroso u ordenado, asociados de manera que formen una unidad, sencilla y unívoca en su lectura para que la decodificación del mensaje sea efectiva. Vidal Silva (2004, p. 49) lo sintetiza diciendo: «... no son una simple ilustración y un texto sino un todo integrado, donde palabras e imágenes se complementan a la perfección y el espacio se integra también, como un elemento más, en el resultado final».

De igual forma, entonces, hay que tener en cuenta la decodificación del mensaje. Gómez Pérez (2002, p. 210-214) plantea una serie de estamentos por los que se filtra la codificación y descodificación del mensaje. No se utilizan únicamente elementos analógicos, sino que existen determinadas unidades arbitrarias que comunican tanto o más. Así, el autor habla de imágenes que comunican por representar analógicamente a unos referentes reales, como los actores, objetos (pistolas, caballos,...), acciones (peleas, baile,...), etc. Además, estos elementos analógicos poseen una información amplificada por la codificación cultural de la que coparticipamos. Y también hay que tener en cuenta la codificación que tradicionalmente ha caracterizado a cada uno de los géneros cinematográficos, tanto desde el punto de vista gráfico como textual o tipográfico. En consecuencia, el autor concluye diciendo: «Con esta conversión de lo analógico en arbitrario y lo arbitrario en analógico parece fácil desmontar la premisa de lectura global para la imagen exclusivamente, y lineal para el texto. Todo cartel puede ser, debe ser y, de hecho, lo es, consciente e inconscientemente, leído y visto tanto de forma global, como de forma lineal. Podríamos hacer una lectura de toda la trama filmica con una «visión lineal» de las imágenes. Asimismo podemos discernir desde el primer golpe visual el género en el que se ubica el filme publicitado».

\section{Conclusiones}

El cartel cinematográfico, pese a que hoy en día forma parte de una extensa campaña en medios y soportes, sigue cumpliendo la principal función para la que es creado: dar a conocer una película y atraer al público hacia la sala cinematográfica, por lo que subsiste gracias a su rentabilidad y eficacia.

$\mathrm{Su}$ propia existencia y características, tanto formales como gráficas, dependen de muchos factores, algunos más técnicos y otros más subordinados al producto que publicita, pero se convierte en una pieza clave para crear una unidad de estilo entre la película y el público.

Su composición responde a aquellos recursos más vendibles, por lo que las distintas estrategias gráficas se apoyan en la estructura narrativa, el star-system y la visualidad de la propia película, por lo que, al margen de su calidad gráfica o estilística, responden a una clara perspectiva mercantilista para el reclamo de espectadores en el momento inmediato del consumo del producto: la sala cinematográfica.

Además de llamar la atención del espectador sobre la película que anuncia, la posiciona de manera rápida y sencilla en la mente del público, utilizando el recurso del género cinematográfico, el estilo, los personajes, comunicando las principales fortalezas del filme, destacando aspectos relevantes de la historia y esperados por el público, etc. Y todo ello sin atender a esquemas, estereotipos o ideas temáticas preconcebidas, sin mediocridad en su diseño, en su código cromático o tipográfico.

No obstante, el auge de los medios digitales y la web 2.0 ha propiciado la aparición de nuevos 
formatos y herramientas de comunicación en las que los usuarios pueden descargar, compartir, construir y generar contenidos relacionados con la propia película, permitiendo así que el público participe del producto y consiguiendo entonces mayores niveles de implicación. La red, por tanto, ha conseguido que cada película exija nuevos retos de promoción para los distribuidores.

Y el cartel ha conseguido no sólo mantenerse como soporte esencial de promoción cinematográfica, sino que se va adaptando a estas nuevas tecnologías y medios digitales sin abandonar su puesto privilegiado a la entrada de la sala cinematográfica. Podemos poner de ejemplo la aparición y desarrollo de lo que se conoce como motion poster, considerado algo más que un cartel electrónico o un cartel que se mueve, pues al igual que su homólogo el cartel de cine tradicional, pretende combinar para cada producto un concepto creativo, utilizando imágenes estáticas con animación, efectos especiales y de diseño gráfico y, de esta manera, cautivar de inmediato la atención del espectador.

\section{Bibliografía}

Alcacer Garmendia, J. A. (1991). El mundo del cartel. Madrid: Granada, D.L.

Baldó, M. y Vernís, P. (2009). Introducción al Marketing Cinematográfico. En Distribución y Marketing Cinematográfico. Manual de primeros auxilios. Barcelona: Publicaciones y Ediciones de la Universidad de Barcelona.

Calvo Herrera, C. (2011). Marketing cinematográfico off line y on line. Derecom, $n^{\circ} 6, \mathrm{~s} / \mathrm{n}$.

Eguizábal, R. (2000): Memoria de la Seducción. Carteles del Siglo XIX en la Biblioteca Nacional. Madrid: Biblioteca Nacional.

Enel, F. (1974). El cartel. Lenguaje, funciones, retórica. Valencia: Fernando Torres Editores.

García García, F. (2007): Una retórica de la publicidad: de la naturaleza inventiva a la verdad metafórica. Pensar la Publicidad, vol. I, núm. 2. 167-183.

Garófano Sánchez, R. (1989). Saber de imágenes: el cartel, el cómic y el cine. Cádiz: Caja de Ahorros de Cádiz.

Gómez Pérez FJ. (2002). La tipografía en el cartel cinematográfico. Comunicación: revista internacional de Comunicación Audiovisual, Publicidad y Estudios Culturales, no 1. 203-216.
Hueso Monton, A. L. El cartel cinematográfico, reclamo y estética. Disponible en: «www.macuf.es/pdfs/sp05_Bunuel_AngelLuisHuesoMonton.pdf» Extraído el 2 de febrero de 2011.

Moles, A. A. (1976). El afiche en la sociedad urbana. Barcelona: Paidós.

Perales Bazo, F. (1995). Cine y publicidad: el afiche cinematográfico. En Algunas consideraciones sobre la comunicación empresarial e institucional. Sevilla: MAECEI.

- (1999). El cartel cinematográfico. [S.L.]: Junta de Andalucía, Conserjería de Cultura.

Pérez Perucha, J. (1986). Escaparates del espectáculo o indicadores del sentido. En Cine / Impreso. Cartelistas españoles de cine 1955-1985. La Coruña: Ayuntamiento de La Coruña, Gobierno Municipal.

Pérez Rufí, J. P. (2010). El cartel de cine hoy. Pensar la Publicidad, vol. IV, $n^{\circ} 2,71-88$.

Rey, J. (1997). El iconismo gráfico en la escritura publicitaria. Questiones Publicitarias, $n^{\circ}$ 6. 9-38.

Sánchez López, R. (1997): El cartel de cine. Arte y Publicidad. Zaragoza: Prensas Universitarias de Zaragoza. 
Serrano Mora, A. (2009). El cine español a través de sus carteles. Iconografía y retórica. Historia de un discurso. Tesis doctoral inédita. Facultad de Ciencias de la Información, Departamento de Comunicación Audiovisual y Publicidad, Madrid.

Tranche, R. R. (1994). El cartel de cine en el engranaje del Star System. Archivos de la Filmoteca, no 18, 135-143.

Vernis, P. (2003). Marketing de cine: herramientas para un oficio arriesgado. Investigación y Marketing, nº 81, 18-22.
Vidal Silva, P. (2004). Inspiración, Arte y Técnica en los carteles de Rafael Morante". AGR, Coleccionistas de cine, núm 22. 44-73.

- (2006): Sólo para tus ojos. AGR, Coleccionistas de cine, núm 31. 92-117.

- (2007): «Caras con ángel» en AGR, Coleccionistas de cine, núm 34. 108-131.

Vogel, H.L. (2004). La industria de la cultura y el ocio. Un análisis económico. Madrid: Fundación Autor. 
